\title{
Regulation of Myocardial Glucose Transporters GLUT1 and GLUT4 in Chronically Anemic Fetal Lambs
}

\author{
J. CARTER RALPHE, PETER N. NAU, CHRISTOPHER E. MASCIO, JEFFREY L. SEGAR, \\ AND THOMAS D. SCHOLZ \\ Department of Pediatrics [J.C.R., P.N.N., J.L.S., T.D.S.], Department of Surgery [C.E.M.], \\ University of Iowa, Iowa City, Iowa 52242
}

\begin{tabular}{|c|c|}
\hline \multicolumn{2}{|c|}{ ABSTRACT } \\
\hline $\begin{array}{l}\text { Little is known about the chronic adaptations that take place } \\
\text { in the fetal heart to allow for increased substrate delivery in } \\
\text { response to chronic stress. Because glucose is an important fuel } \\
\text { for the fetal cardiomyocytes, we hypothesized that myocardial } \\
\text { glucose transporters } 1 \text { and } 4 \text { (GLUT1 and GLUT4, respectively) } \\
\text { are up-regulated in the fetal sheep heart that is chronically } \\
\text { stressed by anemia. Fetal sheep at } 128 \text { d gestation underwent } \\
\text { daily isovolumic hemorrhage and determination of myocardial } \\
\text { blood flow, oxygen consumption, and substrate utilization. At the } \\
\text { end of } 3 \text { or } 7 \text { d of anemia, myocardial levels of GLUT1 and } \\
\text { GLUT4 mRNA and protein were measured and subcellular } \\
\text { localization was determined. Despite stable heart rate and blood } \\
\text { pressure, anemia caused a nearly 4-fold increase in right and left } \\
\text { ventricular (RV and LV) free wall blood flow. No significant } \\
\text { change in myocardial glucose uptake was found and serum } \\
\text { insulin levels remained stable. Both 3-d RV and LV and 7-d RV } \\
\text { mRNA and protein levels of GLUT1 and GLUT4 were un- } \\
\text { changed; 7-d LV GLUT1 and GLUT4 mRNA levels were also } \\
\text { stable. However, LV GLUT1 protein levels declined signifi- } \\
\text { cantly, whereas LV GLUT4 protein levels were increased. In the }\end{array}$ & $\begin{array}{l}\text { steady state, GLUT4 protein localized to the sarcolemma mem- } \\
\text { brane. These findings suggest that the glucose transporters are } \\
\text { post-transcriptionally regulated in myocardium of chronically } \\
\text { anemic fetal sheep with changes that mimic normal postnatal } \\
\text { development. Unlike the postnatal heart, localization of GLUT4 } \\
\text { to the cell membrane suggests the importance of GLUT4 in basal } \\
\text { glucose uptake in the stressed fetal heart. (Pediatr Res 58: } \\
\text { 713-718, 2005) } \\
\text { ERK, extracellular-regulated kinase } \\
\text { GLUT1(4), glucose transporter } 1 \text { (4) } \\
\text { HIF-1 } \alpha \text {, hypoxia-inducible factor } 1 \alpha \\
\text { LV, left ventricular } \\
\text { MAP, mitogen-activated protein } \\
\text { MKP-3, mitogen-activated protein kinase phosphatase-3 } \\
\text { Na }{ }^{+} \text {-K }{ }^{+} \text {ATPase, sodium-potassium ATPase } \\
\text { RV, right ventricular } \\
\text { SL, sarcolemma } \\
\text { SR, sarcoplasmic reticulum }\end{array}$ \\
\hline
\end{tabular}

The heart of the anemic fetus must adapt to an increased workload in the face of decreased oxygen carrying capacity of the blood. In fetal sheep, several hemodynamic adaptations occur acutely that serve to maintain optimal tissue perfusion. Arteriolar resistance to vital organs, including the heart, brain, and adrenal glands, declines, allowing preservation of adequate substrate delivery (1). Stroke volume increases, along with cardiac work, to support the compensatory increase in cardiac output (2).

Chronically, anemia has a profound affect on myocardial architecture, including biventricular hypertrophy accompanied

Received January 7, 2004; accepted February 14, 2005

Correspondence: Thomas D. Scholz, M.D., Department of Pediatrics, 2852 JPP, University of Iowa, 200 Hawkins Dr., Iowa City, IA 52242; e-mail: thomas-scholz@uiowa.edu

This work was supported by the National Institutes of Health, grants T32-HL-07413 (J.C.R.), R01-HL-64770 (J.L.S.), and K02-HL-04495 (T.D.S.).

These studies were presented in part at the Pediatric Academic Societies Annual Meeting, May 3-6, 2003, Seattle, WA.

DOI: 10.1203/01.PDR.0000180546.42475.69 by myocardial vessel growth, as demonstrated by an increase in minimal capillary diameter and a reduction in intercapillary distance $(3,4)$. These adaptations serve to decrease ventricular wall stress and provide enhanced myocardial substrate and oxygen delivery. Interestingly, even with myocardial vessel growth, coronary flow reserve is maintained, allowing the heart to respond to additional stresses placed on the fetus (5).

Metabolic adaptations must accompany the structural changes of the myocardium as cardiac workload increases with acute anemia and is maintained at elevated levels with chronic anemia. An increase in substrate delivery to the myocyte is crucial if normal function is to be maintained. The fetal heart primarily oxidizes glucose and lactate to generate ATP (6), and, in the chronically anemic fetal heart, ATP production continues to occur aerobically despite a 4- to 8-fold increase in serum lactate levels $(3,5)$. At the cardiomyocyte sarcolemma membrane, glucose uptake occurs primarily via two carriers, the glucose transporters 1 and 4 (GLUT1 and GLUT4) (7). In the fetal heart, GLUT1 is responsible for basal glucose uptake 
and is expressed to a greater extent than GLUT4, although developmental increases in GLUT4 have been found (8). In the mature heart, GLUT4 is present in intracellular vesicles and translocates to the cell membrane in response to stimuli such as insulin (9) or hypoxia/ischemia (10) to enhance myocardial glucose uptake during these periods of stress. Importantly, the fetal ovine heart has been shown to vary its expression of GLUT1 and GLUT4 when faced with a perturbation in substrate delivery $(11,12)$. To accommodate the increased workload faced by the heart in the chronically anemic fetus and the need for additional ATP production, an increase in substrate uptake must also occur. The goal of this study was to determine whether increased expression of GLUT1 and GLUT4 occurs in the chronically anemic fetal heart and thereby provides a mechanism to enhance glucose delivery to the stressed myocytes.

\section{METHODS}

Animal preparation. All studies were performed using pregnant ewes of Dorset and Suffolk mixed breeding, obtained from a local source. The gestational ages were based on the induced ovulation technique as described elsewhere (13).

Anesthesia and surgical techniques to cannulate the 128-d fetuses (term $=$ 145 d) have been described previously (14). Briefly, after a 24-h fast of the pregnant ewe, general anesthesia was induced with a mixture of halothane $(1 \%)$, oxygen $(33 \%)$, and nitrous oxide $(66 \%)$. Under sterile conditions, a uterine incision was made and the fetus exteriorized. For animals that were to undergo the chronic anemia protocol along with measurement of myocardial blood flow and myocardial substrate utilization, the fetal thorax was opened and catheters were secured in the left atrial appendage [used solely for microsphere injections (see below)] and placed in the azygous vein. The latter catheter was advanced into the coronary sinus and the azygous sutured tightly around the catheter. A catheter was also placed in the carotid artery and the tip advanced to the proximal ascending aorta. This catheter was used to obtain reference blood samples during microsphere injection and arterial oxygen content and glucose and lactate concentrations. After closure of the chest (or solely in animals that were not injected with microspheres), femoral venous and arterial catheters were placed and the fetus returned to the uterus.

After a 72-h recovering period, daily isovolumic hemorrhage was performed by removal of $80-100 \mathrm{~mL}$ of blood and simultaneous replacement with warmed normal saline. Daily measurements of heart rate, blood pressure, and arterial blood gases were made. Fluorescent microspheres were injected into the left atrium before initiating bleeding and before harvesting fetal tissues to measure myocardial blood flow (see below). After $3 \mathrm{~d}(n=4)$ or $7 \mathrm{~d}(n=13)$ of hemorrhage or sham blood removal, the ewe was again anesthetized as above and the fetuses removed. Fetal tissues were weighed and flash frozen in liquid nitrogen. Animals of either sex were used. Sham controls $(n=13)$ were similarly instrumented although no hemorrhage was performed.

All procedures were performed within the regulations of the Animal Welfare Act and the National Institutes of Health Guide for the Care and Use of Laboratory Animals and were approved by the University of Iowa Animal Care and Use Committee.

Northern blot analyses. Measurements of steady-state mRNA levels of GLUT1 and GLUT4 were made as described previously (15). Total RNA was isolated from the right or left ventricular free wall of the chronic anemic or sham control fetuses. Ovine-specific cDNA probes were prepared to enhance signal-to-noise of the d- ${ }^{32}$ UTP signal of the Northern blots. Hybridization signals were quantitated using a phosphorimager (Molecular Dynamics, Sunnyvale, CA). After study with the specific GLUT1 or GLUT4 probes, blots were stripped and rehybridized with ${ }^{32} \mathrm{P}$-labeled probe to the $18 \mathrm{~S}$ subunit of ribosomal RNA to normalize for variable RNA loading.

Quantitative immunoblots. Immunoblots were prepared as described previously (15) using protein isolated from the left or right ventricular free walls. Antibodies to GLUT1 and GLUT4 proteins were obtained from a commercial source (Santa Cruz Biotechnology, Santa Cruz, CA). The secondary antibody used to detect the primary antibodies was conjugated with horseradish peroxidase. Detection of the secondary antibody using the Pierce SuperSignal Kit (Pierce Biotechnology, Inc., Rockford, IL) was performed and used to expose Kodak XAR film at room temperature. Films were digitized and signals quantitated using NIH Image (Wayne Rasband, National Institutes of Health).
Serial protein dilutions were tested with each antibody to assure quantitated signals were in the linear range for added protein. Immunoblots for each antibody were done at least in triplicate.

Membrane fractionation. To qualitatively assess the intracellular localization of GLUT4 protein, separation of the SL and SR membranes was performed as described by Pitts (16) and modified by Park et al. (17). Briefly, frozen myocardial samples were pulverized in liquid nitrogen then homoge-

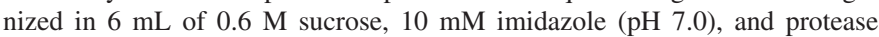
inhibitors leupeptin $(20 \mu \mathrm{g} / \mathrm{mL})$, aprotinin $(2.1 \mu \mathrm{g} / \mathrm{mL})$, and phenylmethanesulfonyl fluoride $(100 \mu \mathrm{g} / \mathrm{mL})$. After centrifugation at $12,000 \times g$ for $30 \mathrm{~min}$ at $4^{\circ} \mathrm{C}$, the supernatant was diluted in $8 \mathrm{~mL} 160 \mathrm{mM}$ potassium chloride and $20 \mathrm{mM}$ 3-morpholinopropanesulfonic acid (KCl/MOPS buffer) at $\mathrm{pH}$ 7.4. The diluted supernatant was centrifuged at $95,000 \times \mathrm{g}$ for $30 \mathrm{~min}$ and the pellet was resuspended in $6 \mathrm{~mL}$ of $\mathrm{KCl} / \mathrm{MOPS}$ buffer using a blade homogenizer. The resuspended pellet was carefully layered onto $7 \mathrm{~mL}$ of $30 \%$ sucrose dissolved in $0.3 \mathrm{M} \mathrm{KCl}$ and $0.1 \mathrm{M}$ Tris- $\mathrm{HCl}(\mathrm{pH} 8.3)$ and centrifuged at $95,000 \times g$ at $4^{\circ} \mathrm{C}$ for $90 \mathrm{~min}$. The band at the gradient interface (SL fraction) was diluted in at least five volumes $\mathrm{KCl} / \mathrm{MOPS}$ buffer and pelleted at $100,000 \times \mathrm{g}$ for $30 \mathrm{~min}$. Pellets from the second $95,000 \times g$ (SR fraction) and the $100,000 \times g$ (SL fraction) spin were resuspended in $50 \mathrm{mM}$ Tris $/ 10 \mathrm{mM}$ EDTA/ $150 \mathrm{mM}$ $\mathrm{NaCl} / 0.1 \%$ mercaptoethanol (containing the protease inhibitors listed above) and then sonicated for $20 \mathrm{~s}$ before immunoblot studies. Relative purity of the SL and SR fractions was verified by showing enhanced concentration of $\mathrm{Na}^{+}-\mathrm{K}^{+}$ATPase and sarcoplasmic reticulum $\mathrm{Ca}^{2+}$-ATPase (SERCA), respectively, by immunoblot using antibodies obtained from a commercial source (Santa Cruz Biotechnology).

Myocardial blood flow measurement. Myocardial blood flow was determined using fluorescent microspheres as described previously (18). Briefly, for each blood flow determination, approximately $1.2 \times 10^{6} 15 \mu \mathrm{m}$ fluorescentlabeled polystyrene microspheres (Triton Technology, San Diego, CA) suspended in $1 \mathrm{~mL} 0.9 \% \mathrm{NaCl}$ with $0.02 \%$ Tween and $0.02 \%$ thimerosal, were injected into the left atrium and flushed with $2 \mathrm{~mL} 0.9 \% \mathrm{NaCl}$ over a $30-\mathrm{s}$ period. Beginning $25 \mathrm{~s}$ before the microsphere injection, reference blood samples were withdrawn from the $1.14 \mathrm{~mm}$ internal diameter carotid catheter (tip in the ascending aorta) into heparinized glass syringes for $2.5 \mathrm{~min}$ at a rate of $2 \mathrm{~mL} / \mathrm{min}$. Samples of blood and known weights myocardium were digested and filtered to recover microspheres using previously published methodologies ("Manual for Using Fluorescent Microspheres to Measure Regional Organ Perfusion," Fluorescent Microsphere Resource Center, University of Washington; available at http://fmrc.pulmcc.washington.edu). After digestion, the microspheres were filtered from the solutions using $10 \mu \mathrm{m}$ filter membranes (Triton Technology). Microspheres were dissolved with $1000 \mu \mathrm{L}$ of Cellosolve acetate (Fisher Scientific, Fair Lawn, NJ) and $200 \mu \mathrm{L}$ of solution was transferred to a well plate and fluorescence was determined. Fluorescent measurements of experimental and "standard curve" samples were determined with a luminescence spectrophotometer (LS-50B, PerkinElmer, Wellesley, MA) using the appropriate excitation/emission wavelengths and slit widths for the given colored sphere. Tissue blood flow (using ascending aorta reference samples) was calculated using the formula:

$$
\mathrm{Q}_{\text {sample }}=\left(\mathrm{Q}_{\text {ref }} \times \mathrm{F}_{\text {sample }}\right) / \mathrm{F}_{\text {ref }}
$$

where $\mathrm{Q}_{\text {sample }}$ and $\mathrm{Q}_{\text {ref }}$ are the blood flow (in $\mathrm{mL} / \mathrm{min}$ ) in the specific sample, respectively, and $\mathrm{F}_{\text {sample }}$ and $\mathrm{F}_{\text {ref }}$ are the fluorescent intensities in the specific sample and reference sample, respectively.

Left ventricular substrate utilization determination. As described above, catheters positioned in the ascending aorta and coronary sinus were used to measure left ventricular oxygen, glucose, and lactate uptake. Oxygen content measurements were made using a co-oximeter (Instrumentation Laboratories, Lexington, MA) whereas glucose and lactate measurements were made using a YSI Glucose/Lactate Analyzer (YSI Inc., Yellow Springs, OH). Arterialvenous differences were determined and multiplied by the average of the left ventricular endocardial and epicardial blood flows determined from the fluorescent microsphere measurements.

Sheep serum insulin was measured using a solid-phase RIA kit (Coat-ACount Insulin, Diagnostic Products, Los Angeles, CA). Serum samples were measured directly without prior extraction or dilution. The lowest concentration of insulin that can be reliably measured using this test method was 1.0 $\mu \mathrm{IU} / \mathrm{mL}$. The intra- and interassay coefficients of variation averaged $2.0 \%$ and $7.3 \%$, respectively.

Statistics. All data are expressed as mean \pm SEM. Comparisons between the chronic anemic and control groups were made by unpaired $t$ test. Significant differences were identified at the $p<0.05$ level. 


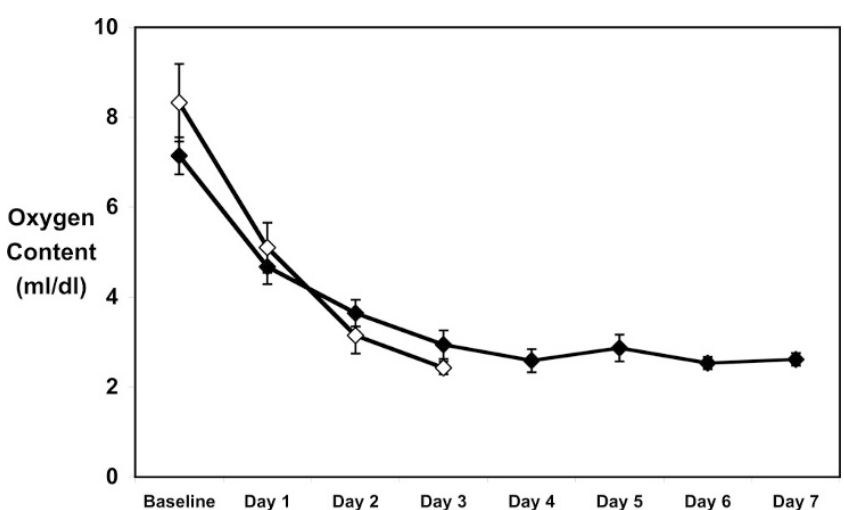

Figure 1. Fetal oxygen content after isovolumic hemorrhage. Fetal sheep underwent 3 or $7 \mathrm{~d}$ of isovolumic hemorrhage starting at $135 \mathrm{~d}$ gestation. Arterial oxygen content and $\mathrm{Hb}$ were measured and used to calculate arterial oxygen content. $\diamond 3$-d Anemia. $\diamond$-d Anemia.

\section{RESULTS}

During the period of anemia, a similar progressive decline in arterial oxygen content occurred in both the 3-d and 7-d animals, reaching a final value of $2.4 \pm 0.1 \mathrm{~mL} / \mathrm{dL}$ in the $3-\mathrm{d}$ and $2.6 \pm 0.1 \mathrm{~mL} / \mathrm{dL}$ in the 7 -d fetuses (Fig. 1). This fall in oxygen content reflected a significant decline in $\mathrm{Hb}$ in both the 3-d and 7-d fetuses (Table 1). Mean arterial pressure, heart rate, and arterial $\mathrm{pH}$ remained stable during the period of anemia in both groups of animals (Table 1).

Myocardial blood flow was measured at the beginning and end of the 7-d anemia period in four animals using fluorescent microspheres. As summarized in Table 2, blood flow to both the endocardium and epicardium of the right and left ventricles was significantly increased after $7 \mathrm{~d}$ of anemia compared with baseline measurements made in the same animals.

Left ventricular oxygen consumption was determined based on an average of the LV endocardium and epicardium blood flows and the difference in oxygen content between the aorta and coronary sinus. Although myocardial oxygen consumption was increased, variability of the data and the small number of samples precluded identification of a significant difference (Table 2). Left ventricular utilization of glucose and lactate was also determined at baseline and at the end of the 7-d study period of anemia. As shown in Table 2, both glucose and lactate uptake remained stable at the two time points. However, serum lactate levels increased significantly in the animals at $7 \mathrm{~d}$ of anemia (baseline lactate, $1.33 \pm 0.27 \mathrm{mM}$; 7-d anemia lactate, $2.94 \pm 0.62 \mathrm{mM} ; n=4 ; p<0.05$ ).

Myocardial expression of the glucose transporters GLUT1 and GLUT4 at the mRNA and protein levels was compared in 7-d anemic and control fetuses. Myocardium from both the
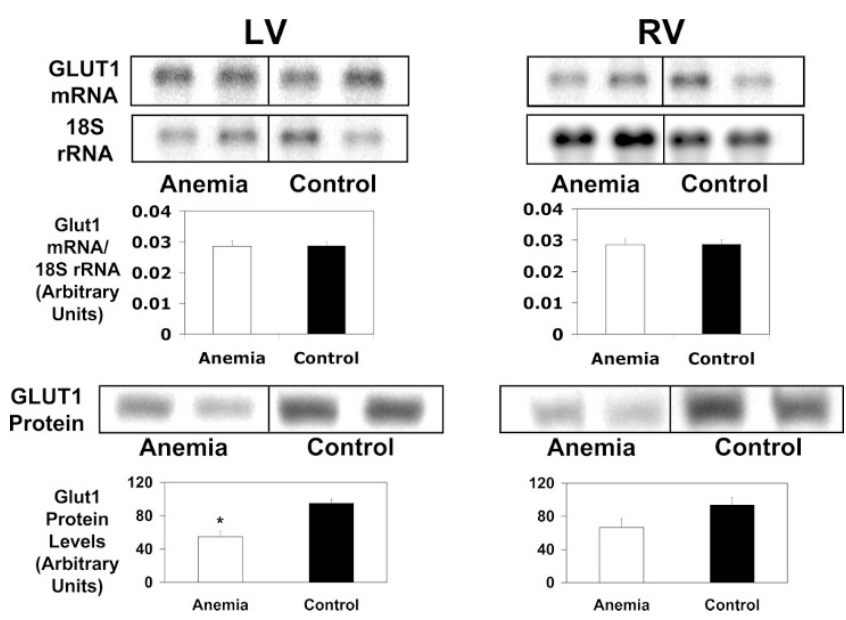

Figure 2. Steady state GLUT1 mRNA and protein levels. Samples of right and left ventricular (RV and LV) free wall from 7-d anemia and control animals were sampled. The top panel shows representative lanes of the Northern blot using an ovine-specific ${ }^{32} \mathrm{P}$-labeled probe to GLUT1. Membranes were re-probed with a probe to the $18 \mathrm{~S}$ rRNA to correct for variable RNA loading. Quantitated ${ }^{32} \mathrm{P}$ signals are shown in the plot $(n=11$ for RV and 12 for LV). The lower panel shows representative lanes of an immunoblot using an anti-GLUT1 antibody to determine steady-state GLUT1 protein levels in the RV and LV free walls of 7-d anemic and control animals. Chemiluminescent signals were quantitated and are shown in the lower plots $(n=13)$. ${ }^{*} p$ $<0.05$ by unpaired $t$ test.

right and left ventricular free walls was sampled for study. Steady state mRNA levels of GLUT1 were similar in control and 7-d anemic fetuses of both ventricles (Fig. 2). At the protein level, GLUT1 levels were lower in the myocardium of anemic animals, declining significantly in the left ventricular free wall tissue. Similar to GLUT1, steady state mRNA levels of GLUT4 remained unchanged in anemic right and left ventricular myocardium compared with controls (Fig. 3). Myocardial protein levels of GLUT4, however, were significantly increased in the left ventricle from anemic animals. Right ventricular GLUT4 protein levels were unchanged.

To examine the time course of the changes in GLUT1 and GLUT4 protein levels and to determine whether any early increases in GLUT1 or GLUT4 gene expression occurred, additional Northern and Western blot studies were performed on a separate group of animals after $4 \mathrm{~d}$ of anemia $(n=4)$. In both the right and left ventricular myocardium of these 4-d anemic animals, no change in mRNA or protein levels of GLUT1 and GLUT4 were found in comparison to sham controls (data not shown).

Transcription of the GLUT4 gene and cellular localization of the GLUT4 protein is regulated by serum insulin $(9,19)$. Because of this well-defined relationship, serum insulin levels

Table 1. Hemodynamic and Physiologic Measurements of the Anemic Ovine Fetuses

\begin{tabular}{lcccc}
\hline & 3-d Anemia Baseline & 3-d Anemia Day 3 & 7-d Anemia Baseline & 7-d Anemia Day 7 \\
$(\mathrm{n}=7)$ & $(\mathrm{n}=4)$ & $5.2 \pm 0.4^{*}$ \\
Hemoglobin (mg/dl) & $(\mathrm{n}=4)$ & $5.4 \pm 0.8^{*}$ & $11.5 \pm 0.5$ & $48 \pm 1$ \\
Mean Arterial Pressure (mmHg) & $10.8 \pm 0.4$ & $38 \pm 2$ & $48 \pm 2$ & $180 \pm 4$ \\
Heart Rate (beats/min) & $44 \pm 2$ & $180 \pm 2$ & $7.38 \pm 0.01$ & $171 \pm 5$ \\
Arterial pH & $174 \pm 17$ & $7.38 \pm 0.01$ & $7.36 \pm 0.01$ \\
\hline
\end{tabular}

$\mathrm{LV}=$ left ventricular; $\mathrm{RV}=$ right ventricular; $* \mathrm{p}<0.05$ versus Baseline. 
Table 2. Blood Flow and Myocardial Substrate Utilization Measurements of the Anemic Ovine Fetuses

\begin{tabular}{|c|c|c|c|}
\hline & $\mathrm{N}$ & Baseline & Anemia Day 7 \\
\hline $\begin{array}{l}\text { LV Endocardial Blood } \\
\text { Flow }(\mathrm{ml} / \mathrm{min} / 100 \mathrm{~g})\end{array}$ & 4 & $181 \pm 60$ & $654 \pm 177^{*}$ \\
\hline $\begin{array}{l}\text { LV Epicardial Blood Flow } \\
(\mathrm{ml} / \mathrm{min} / 100 \mathrm{~g})\end{array}$ & 4 & $160 \pm 57$ & $560 \pm 119^{*}$ \\
\hline $\begin{array}{l}\text { RV Endocardial Blood } \\
\text { Flow }(\mathrm{ml} / \mathrm{min} / 100 \mathrm{~g})\end{array}$ & 4 & $179 \pm 49$ & $738 \pm 160 *$ \\
\hline $\begin{array}{l}\text { RV Epicardial Blood Flow } \\
(\mathrm{ml} / \mathrm{min} / 100 \mathrm{~g})\end{array}$ & 4 & $210 \pm 53$ & $920 \pm 186^{*}$ \\
\hline $\mathrm{MVO}_{2}(\mu \mathrm{mol} / \mathrm{min} / 100 \mathrm{~g})$ & 4 & $24.0 \pm 10.9$ & $48.4 \pm 12.6$ \\
\hline $\begin{array}{l}\text { LV Glucose Uptake } \\
\text { (mg/min/100g) }\end{array}$ & 4 & $26.9 \pm 7.9$ & $38.0 \pm 25.2$ \\
\hline $\begin{array}{l}\text { LV Lactate Uptake } \\
(\mathrm{mg} / \mathrm{min} / 100 \mathrm{~g})\end{array}$ & 4 & $5.5 \pm 3.1$ & $5.9 \pm 3.2$ \\
\hline
\end{tabular}

$\mathrm{LV}=$ left ventricular; $\mathrm{RV}=$ right ventricular; $\mathrm{MVO}_{2}=$ myocardial oxygen consumption; * $\mathrm{p}<0.05$ versus Baseline.
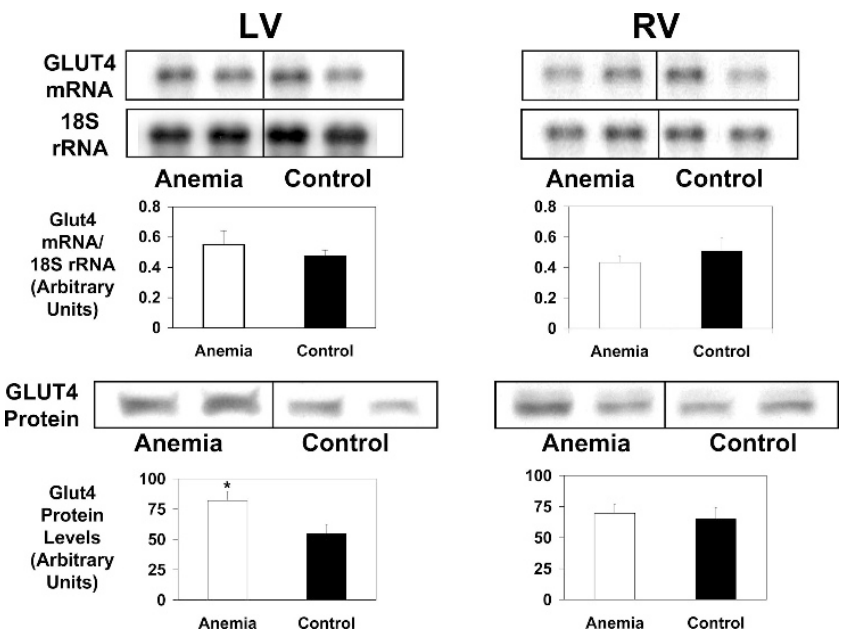

Figure 3. Steady state GLUT4 mRNA and protein levels. Samples of right and left ventricular (RV and LV) free wall from 7-d anemia and control animals were sampled. The top panel shows representative lanes of the Northern blot using an ovine-specific ${ }^{32} \mathrm{P}$-labeled probe to GLUT4. Membranes were re-probed with a probe to the $18 \mathrm{~S}$ rRNA to correct for variable RNA loading. Quantitated ${ }^{32} \mathrm{P}$ signals are shown in the plot $(n=12$ for $\mathrm{RV}$ and 11 for LV). The lower panel shows representative lanes of an immunoblot using an anti-GLUT4 antibody to determine steady-state GLUT4 protein levels in the RV and LV free walls of 7-d anemic and control animals. Chemiluminescent signals were quantitated and are shown in the lower plots $(n=13){ }^{*} p$ $<0.05$ by unpaired $t$ test.

were determined by RIA in the 7-d anemic fetal sheep at baseline before the start of the daily bleeding, at $3 \mathrm{~d}$, and at $7 \mathrm{~d}$. No significant difference was found in serum insulin levels at any of these three time points in the anemic animals $(0 \mathrm{~d}$ : $1.8 \pm 0.4 ; 3 \mathrm{~d}: 1.5 \pm 0.3 ; 7 \mathrm{~d}: 1.7 \pm 0.3 \mu \mathrm{U} / \mathrm{mL} ; n=5$ ).

The intracellular localization of GLUT4 in the left ventricular myocytes of the control and anemic animals was also investigated. Left ventricular samples were separated into a SL membrane fraction (outer cell membrane) and a SR membrane fraction (inner cell membranes). The effectiveness of the membrane fractionation method was verified by immunoblot using an antibody to $\mathrm{Na}^{+}-\mathrm{K}^{+}$ATPase, an outer membrane protein, and SERCA, a protein found in sarcoplasmic reticulum (Fig. 4). Although some samples retained some SL membranes (as seen by the presence of $\mathrm{Na}^{+}-\mathrm{K}^{+}$ATPase in the SR fraction and

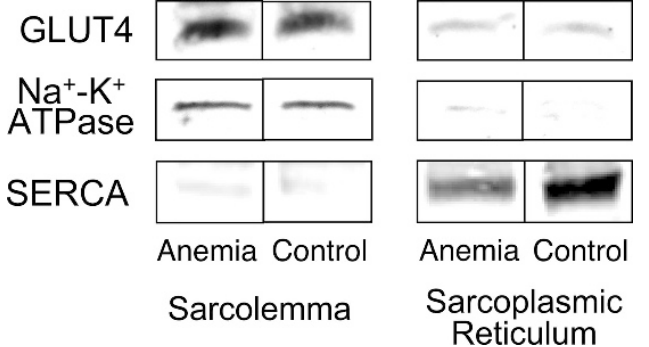

Figure 4. Subcellular localization of GLUT4. Left ventricular free wall samples of 7-d anemia and control animals were fractionated into outer SL membranes and inner SR membranes. Protein samples were separated by SDS-PAGE and membranes probed with either anti-GLUT4 antibody, an antibody to the outer membrane protein $\mathrm{Na}^{+}-\mathrm{K}^{+}$ATPase, or an antibody to SR calcium-ATPase (SERCA). The $\mathrm{Na}^{+}-\mathrm{K}^{+}$ATPase and SERCA immunoblots were used to demonstrate adequate separation of the cell membrane fractions.

some SERCA in the SL fraction in Fig. 4), the GLUT4 protein was found to be predominantly localized to the SL membrane fraction in both chronically anemic and control animals.

\section{DISCUSSION}

Hemodynamic and metabolic response of the chronically anemic fetal heart. The effect of arterial hypoxemia on fetal hemodynamics has been investigated in both the acute and chronic settings. Acutely, there is a decrease in arteriolar resistance to the vital organs and an increase in cardiac stroke volume $(1,2)$. The heart rate and blood pressure response in the chronically anemic fetal sheep heart has been found to be variable. While the blood pressure was decreased in the anemic animals compared with controls in this study, this difference was not significant. Several investigators have shown little or no change in either heart rate or blood pressure despite greater than 50\% reduction in fetal hematocrit and arterial oxygen content $(3-5,20)$. Cardiac work also appears to increase, although a significant increase in myocardial oxygen consumption was identified in only one study (5).

Decreased arterial oxygen content in the fetal lamb has a profound effect on the myocardial blood flow. Since the heart primarily operates aerobically, coronary flow must increase to provide adequate oxygen delivery. As in this study, others have found 3- to 5-fold increases in myocardial blood flow in the anemic fetus $(3,5,20)$. A threshold level of arterial oxygen content of approximately $6 \mathrm{~mL} / \mathrm{dL}(2500 \mu \mathrm{M})$ appears to exist in both acute and chronic models of fetal hypoxia below which myocardial blood flow increases $(20,21)$.

It is apparent that the adaptive increase in myocardial blood flow supports continued aerobic utilization of glucose and lactate by the cardiac myocyte. The marker of anaerobic metabolism, a shift to lactate production by the myocytes, was not seen in this study or prior investigations $(3,5,20)$. In fact, in the large study by Davis et al. (5), only 2 of 46 samples from anemic fetal lambs demonstrated net lactate production. Continued aerobic metabolism, however, does not occur elsewhere in the body. Systemic lactate levels increased significantly in this and other studies indicating a shift toward anaerobic metabolism $(3,5,20)$. The source of the increase in serum 
lactate concentration has not been determined. The important conclusion from these data is that, despite dramatic declines in arterial oxygen carrying capacity after $7 \mathrm{~d}$ of anemia, the fetal heart does not appear to become significantly hypoxic and the heart continues to aerobically oxidize glucose and lactate.

Glucose transporter expression in the fetal heart. Despite the stable myocardial glucose utilization as found in this study and others after chronic anemia and hypoxia $(5,20)$, the mechanism(s) by which glucose entry is regulated in the fetal cardiac myocyte has not been extensively studied. In the fetus, GLUT1 is the dominant glucose transporter $(8,22,23)$. Postnatally, there is a decline in GLUT1 and an increase in both myocardial GLUT4 mRNA and protein levels $(8,22,23)$. In the postnatal heart, GLUT1 is thought to be responsible for basal glucose uptake during normal flow conditions $(7,9)$. GLUT4, however, is primarily found in an intracellular location and is translocated to the outer cell membrane in response to insulin and other stresses such as hypoxia and ischemia $(7,24,25)$. Chronic anemia in our fetal sheep model caused an interesting adaptation in the myocardial glucose transporters. Levels of GLUT4 protein significantly increased in the LV of the chronically anemic animals while GLUT1 protein levels fell. These changes appeared to occur post-transcriptionally, inasmuch as no significant change in steady state mRNA levels of either GLUT1 or GLUT4 was seen. Furthermore, studies to examine the cellular localization of GLUT4 found that the protein was predominantly associated with the outer cell membrane, in a position where GLUT4 would contribute to glucose uptake. Of note, the sarcolemma localization of GLUT4 occurred in both the control and anemic hearts, suggesting that in the fetal heart, GLUT4 contributes to basal glucose uptake. Studies by He et al. (26) identified a similar preponderance of GLUT4 in the sarcolemma of fetal rat skeletal muscle and a decrease in insulin-mediated translocation of GLUT4 compared with adult, suggesting that glucose transport via GLUT4 significantly contributed to the basal metabolic needs of the muscle.

The origin of the interventricular differences in glucose transporter regulation is not clear. The presence of a patent ductus arteriosus that is nonrestrictive should result in both ventricles facing an equal afterload. Also, both LV and RV blood flows in the 7-d anemic animals increased by a factor of approximately 4 , suggesting that substrate delivery would not have been significantly different between ventricles. The possibility of regional differences in myocardial wall stress and oxygen consumption exists and will require further study.

Regulation of glucose transporter expression. Whereas the regulation of GLUT1 and GLUT4 protein levels in this study appeared to occur at the post-transcriptional level, developmental changes in myocardial levels of these proteins have been shown to correlate with mRNA levels $(23,27)$. In addition, elegant nuclear run-on assays by Santalucia et al. (28) demonstrated an age-related decrease in Glut1 and an increase in Glut4 transcriptional activity. The -99/-33 region of the Glut1 proximal promoter appears to drive transcription and contains the binding site for the Sp1 transcription factor $(28,29)$.

The MAP kinase pathways also contribute to the regulation of Glut1 transcription. In isolated myocytes, transfection with constitutively active Ras or MAP kinase/ERK kinase (MEK1) stimulated expression of a Glutl promoter construct (30). Conversely, transfection with the MAP kinase phosphatase MKP-3 decreased Glut1 promoter activity (30). These data are relevant given recent findings in our laboratory that phosphorylated ERK-1/2 levels are greatly diminished and MKP-3 protein levels are increased in the left ventricle of the anemic fetuses compared with control animals (unpublished data).

The identification of a hypoxia-inducible element upstream from the Glutl gene and its parallel expression with HIF- $1 \alpha$ suggest that the expression of GLUT1 can be induced by hypoxia $(31,32)$. Recent studies by Martin et al. (4) found that the chronically anemic fetal heart increases expression of HIF- $1 \alpha$. The greater levels of HIF- $1 \alpha$ in these stressed hearts were associated with an increase in vascular endothelial growth factor and increased capillarity, thus providing an adaptive increase in coronary perfusion and substrate delivery to the myocardium.

The decrease in GLUT1 protein levels found in the 7-d anemic LV suggests that MAP kinase pathway regulation of Glut1 transcription may have been dominant in this study. It is possible that down-regulation of Glutl transcription occurred at times other than the 3-d and 7-d time points that were examined in this study and that our measurements identified downstream effects of these pathways on GLUT1 protein levels.

Regulation of Glut4 gene expression appears to be equally, if not more, complex than Glut1. A 5'-flanking promoter region has been found that appears to convey insulin-responsive transcriptional activation $(19,33)$. In addition, a novel mechanism of Glut4 transcriptional activation that involved cooperation between MyoD, myocyte enhancer factor-2, and the thyroid hormone receptor TRalpha1 has recently been defined in a skeletal muscle and fibroblast cell lines (34). Given the stable insulin and GLUT4 mRNA levels in the chronic anemia model, the mechanism of the increase in GLUT4 protein level in the anemic fetuses will require further study.

\section{CONCLUSIONS}

The model of chronic anemia in the ovine fetus provides a unique tool for investigating the volume loaded fetal heart. The ability to simultaneously measure hemodynamic parameters, physiologic properties of the myocardium, and expression of genes allows important insights into clinically relevant adaptive responses of the fetal heart. In this study, increased workload experienced by the anemic fetal heart resulted in an apparent acceleration in the normal maturational changes that occur in the expression of myocardial glucose transporter proteins. The increase in left ventricular GLUT4 protein levels in the anemic animals, particularly with the localization of the GLUT4 protein to the sarcolemma membrane, likely contributed to the adaptation of the stressed hearts to the increased metabolic demands imposed by the anemic state. Whether this adaptive response was mediated by MAP kinase or other signaling pathways remains the focus of future investigations.

Acknowledgments. The authors thank Oliva M. Smith and Kurt A. Bedell for technical assistance. 


\section{REFERENCES}

1. Fumia FD, Edelstone DI, Holzman IR 1984 Blood flow and oxygen delivery to feta organs as functions of fetal hematocrit. Am J Obstet Gynecol 150:274-282

2. Kilby MD, Szwarc R, Benson LN, Morrow RJ 1998 Left ventricular hemodynamics in anemic fetal lambs. J Perinat Med 26:5-12

3. Davis LE, Hohimer AR 1991 Hemodynamics and organ blood flow in fetal sheep subjected to chronic anemia. Am J Physiol 261:R1542-R1548

4. Martin C, Yu AY, Jiang BH, Davis L, Kimberly D, Hohimer AR, Semenza GL 1998 Cardiac hypertrophy in chronically anemic fetal sheep: Increased vascularization is associated with increased myocardial expression of vascular endothelial growth factor and hypoxia-inducible factor 1. Am J Obstet Gynecol 178:527-534

5. Davis LE, Hohimer AR, Morton MJ 1999 Myocardial blood flow and coronary reserve in chronically anemic fetal lambs. Am J Physiol 277:R306-R313

6. Fisher DJ, Heymann MA, Rudolph AM 1980 Myocardial oxygen and carbohydrate consumption in fetal lambs in utero and in adult sheep. Am J Physiol 238:H399-H405

7. Devaskar SU, Mueckler MM 1992 The mammalian glucose transporters. Pediatr Res 31:1-13

8. Wang C, Hu SM 1991 Developmental regulation in the expression of rat heart glucose transporters. Biochem Biophys Res Commun 177:1095-1100

9. Kraegen EW, Sowden JA, Halstead MB, Clark PW, Rodnick KJ, Chisholm DJ, James DE 1993 Glucose transporters and in vivo glucose uptake in skeletal and cardiac muscle: fasting, insulin stimulation and immunoisolation studies of GLUT1 and GLUT4. Biochem J 295:287-293

10. Xia Y, Warshaw JB, Haddad GG 1997 Effect of chronic hypoxia on glucose transporters in heart and skeletal muscle of immature and adult rats. Am J Physiol 273:R1734-R1741

11. Das UG, Schroeder RE, Hay WW Jr, Devaskar SU 1999 Time-dependent and tissue-specific effects of circulating glucose on fetal ovine glucose transporters. Am J Physiol 276:R809-R817

12. Anderson MS, Flowers-Ziegler J, Das UG, Hay WW Jr., Devaskar SU 2001 Glucose transporter protein responses to selective hyperglycemia or hyperinsulinemia in fetal sheep. Am J Physiol Regul Integr Comp Physiol 281:R1545-R1552

13. Jennings JJ, Crowley JP 1972 The influence of mating management on fertility in ewes following progesterone-PMS treatment. Vet Res 90:495-498

14. Segar J, Bedell K, Page W, Mazursky J, Nuyt A-M, Robillard J 1995 Effect of cortiso on gene expression of the renin-angiotensin system in fetal sheep. Pediatr Res 37:1-6

15. Nau P, Van Natta T, Ralphe JC, Teneyck CJ, Bedell KA, Caldarone CA, Segar JL, Scholz TD 2002 Metabolic adaptation of the fetal and postnatal ovine heart: regulatory role of hypoxia inducible factor-1 and nuclear respiratory factor-1. Pediatr Res 52:269-278

16. Pitts BJ 1979 Stoichiometry of sodium-calcium exchange in cardiac sarcolemmal vesicles. Coupling to the sodium pump. J Biol Chem 254:6232-6235

17. Park JB, Kim JH, Kim Y, Ha SH, Yoo JS, Du G, Frohman MA, Suh PG, Ryu SH 2000 Cardiac phospholipase D2 localizes to sarcolemmal membranes and is inhibited by alpha-actinin in an ADP-ribosylation factor-reversible manner. J Biol Chem 275:21295-21301

18. Dalshaug GB, Scholz TD, Smith OM, Bedell KA, Caldarone CA, Segar JL 2002 Effects of gestational age on myocardial blood flow and coronary flow reserve in pressure-loaded ovine fetal hearts. Am J Physiol Heart Circ Physiol 282:H1359H1369

19. Olson AL, Pessin JE 1995 Transcriptional regulation of the human GLUT4 gene promoter in diabetic transgenic mice. J Biol Chem 270:23491-23495

20. Fisher DJ, Heymann MA, Rudolph AM 1982 Fetal myocardial oxygen and carbohydrate metabolism in sustained hypoxemia in utero. Am J Physiol 243:H959-H963

21. Peeters LL, Sheldon RE, Jones MD Jr, Makowski EL, Meschia G 1979 Blood flow to fetal organs as a function of arterial oxygen content. Am J Obstet Gynecol 135:637-646

22. Santalucia T, Camps M, Castello A, Munoz P, Nuel A, Testar X, Palacin M, Zorzano A 1992 Developmental regulation of GLUT-1 (erythroid/Hep G2) and GLUT-4 (muscle/fat) glucose transporter expression in rat heart, skeletal muscle, and brown adipose tissue. Endocrinology 130:837-846

23. Postic C, Leturque A, Printz RL, Maulard P, Loizeau M, Granner DK, Girard J 1994 Development and regulation of glucose transporter and hexokinase expression in rat. Am J Physiol 266:E548-E559

24. Slot JW, Geuze HJ, Gigengack S, James DE, Lienhard GE 1991 Translocation of the glucose transporter GLUT4 in cardiac myocytes of the rat. Proc Natl Acad Sci U S A 88:7815-7819

25. Sun D, Nguyen N, DeGrado TR, Schwaiger M, Brosius FC 3rd 1994 Ischemia induces translocation of the insulin-responsive glucose transporter GLUT4 to the plasma membrane of cardiac myocytes. Circulation 89:793-798

26. He J, Thamotharan M, Devaskar SU 2003 Insulin-induced translocation of facilitative glucose transporters in fetal/neonatal rat skeletal muscle. Am J Physiol Regul Integr Comp Physiol 284:R1138-R1146

27. Santalucia T, Camps M, Castello A, Munoz P, Nuel A, Testar X, Palacin M, Zorzano A 1992 Developmental regulation of GLUT-1 (erythroid/Hep G2) and GLUT-4 (muscle/fat) glucose transporter expression in rat heart, skeletal muscle, and brown adipose tissue. Endocrinology 130:837-846

28. Santalucia T, Boheler KR, Brand NJ, Sahye U, Fandos C, Vinals F, Ferre J, Testar X, Palacin M, Zorzano A 1999 Factors involved in GLUT-1 glucose transporter gene transcription in cardiac muscle. J Biol Chem 274:17626-17634

29. Vinals F, Fandos C, Santalucia T, Ferre J, Testar X, Palacin M, Zorzano A 1997 Myogenesis and MyoD down-regulate Sp1. A mechanism for the repression of GLUT1 during muscle cell differentiation. J Biol Chem 272:12913-12921

30. Montessuit C, Thorburn A 1999 Transcriptional activation of the glucose transporter GLUT1 in ventricular cardiac myocytes by hypertrophic agonists. J Biol Chem 274:9006-9012

31. Behrooz A, Ismail-Beigi F 1999 Stimulation of glucose transport by hypoxia: signals and mechanisms. News Physiol Sci 14:105-110

32. Ebert BL, Firth JD, Ratcliffe PJ 1995 Hypoxia and mitochondrial inhibitors regulate expression of glucose transporter-1 via distinct Cis-acting sequences. J Biol Chem 270:29083-29089

33. Petersen S, Bahr M, Eckel J 1995 Insulin-dependent regulation of Glut4 gene expression in ventricular cardiomyocytes: evidence for a direct effect on Glut4 transcription. Biochem Biophys Res Commun 213:533-540

34. Santalucia T, Moreno H, Palacin M, Yacoub MH, Brand NJ, Zorzano A 2001 A novel functional co-operation between MyoD, MEF2 and TRalpha1 is sufficient for the induction of GLUT4 gene transcription. J Mol Biol 314:195-204 